\title{
Travessias imprescindíveis
}

\author{
Maria Helena Serôdio
}

Entrando no sétimo ano da sua existência e cumprindo com uma assinalável regularidade a sua publicação, a revista Sinais de cena marca o campo dos Estudos do teatro e das artes performativas em Portugal em três importantes vertentes: promove a investigação teórica, crítica e histórica (quer na secção "Estudos aplicados", quer no "Arquivo solto"), fomenta a análise de espectáculos, livros e edições online (em "Passos em volta", "Leituras" e "Em rede"), e orienta em dois sentidos vitais a atenção do leitor: por um lado, olhando as razões portuguesas, numa atenção aos artistas que entrevista ("Na primeira pessoa") ou que relembra através de um caderno de imagens ("Portefólio"); por outro, procurando um diálogo com realidades de fora que aqui são trazidas para a secção "Notícias de fora".

E esta bifocalidade repete-se também no "Dossiê temático" que, em Junho, nos fala do Prémio (e das Menções Especiais) da Crítica ao teatro português, mas que em Dezembro vem optando por reunir artigos sobre aspectos temáticos que geralmente derivam de iniciativas internacionais, organizadas ou apoiadas quer pela Associação Portuguesa dos Críticos de Teatro, quer pelo Centro de Estudos de Teatro da Faculdade de Letras da Universidade de Lisboa.

E esta convergência de esforços entre a Associação e o Centro é, sem dúvida alguma, uma preciosa mais-valia na medida em que mutuamente se enriquecem, promovendo - na esfera nacional e internacional - as pontes para uma justa e necessária internacionalização do teatro e dos estudos de teatro do nosso pais. No debate em torno da performance (n. ${ }^{\circ}$ ), ou de Harold Pinter (n. ${ }^{\circ}$ 6), na presente avaliação da ecdótica para os Estudos de teatro (n. ${ }^{\circ}$ 8), na interrogação ao lugar (cada vez mais residual) da crítica de teatro, de dança, ópera e música no mundo de hoje (n. ${ }^{\circ}$ ), na inquirição - transversal - às relações entre "ficções dramatúrgicas e cenográficas" (n. 8), à articulação entre "corpos em palco e práticas cénicas" (n. 10), ou à "violência no teatro" (n. ${ }^{\circ}$ s 10 e 11), entre outros passos da nossa publicação, foram sendo invocados pensamentos e práticas que desenham essas travessias e que colocam aspectos relevantes do nosso teatro - e das nossas artes performativas - em diálogo com algumas das questões candentes com que se debate hoje o teatro no mundo.

Mas essas travessias - geográficas, temáticas e artísticas - estão ainda presentes na publicação de algumas das conferências que o Centro de Estudos de Teatro promove e de que a Sinais de cena dá conta de forma cuidada e - tratando-se de textos estrangeiros - em tradução. É que, para nós, a internacionalização não se esgota no "levar e trazer" como mercadorias a transaccionar em caixote fechado, antes exige e promove a nossa língua (e a nossa cultura) até no simples exercício de procurar os termos mais correctos, como ocorreu várias vezes no confronto com textos "difíceis" de Erika Fischer-Lichte, Alessandro Tinterri, Patrice Pavis, Aleks Sierz ou Marvin Carlson, entre outros. E agilizámos, entretanto, uma outra plataforma internacional com a nossa colaboração activa na criação e desenvolvimento da revista (online) Critical Stages / Scènes critiques, da Associação Internacional de Críticos de Teatro.

Nesta edição da Sinais de cena, com que abrimos o ano de 2010, gostaria de destacar os textos que explicam a atribuição do Prémio da Crítica a Jorge Silva Melo e as Menções Especiais ao figurinista Bernardo Monteiro e à encenadora e actriz Mónica Calle, bem como as análises de espectáculos pelos passos em volta de alguns dos palcos do Porto, Coimbra, Caldas da Rainha, Lisboa e Évora nos seus mais variados procedimentos artísticos e configurações dramatúrgicas. Nuno Carinhas é-nos revelado - em discurso directo - "Na primeira pessoa" e Mário Barradas é recordado numa sequência de imagens do teatro que fez no seu trajecto pela descentralização cultural e artística em Évora. Do mundo lusófono cheganos um artigo sobre processos dramatúrgicos em CaboVerde e um sobre a revista 0 percevejo no Brasil, mas também um artigo de um investigador em França sobre a dramaturgia de Teresa Rita Lopes. E de dramaturgia portuguesa fala ainda Silvina Pereira recordando a leitura de clássicos na Livraria Bulhosa e o trabalho - atento e meticuloso - de Diana Dionísio a reconstituir o trajecto artístico de Manuela Porto, a diseuse que, pela primeira vez em Portugal, disse em público a Ode marítima de Fernando Pessoa (em 1938)

$\mathrm{Na}$ evocação das realidades teatrais noutros pontos do mundo, destaca-se o artigo de Tinterri que nos fala do futurismo italiano (e que, pela referência a Pirandello, não pode deixar de dialogar com o artigo de João Carneiro sobre Jorge Silva Melo) e uma passagem pela ópera de Pequim, pela voz de Anabela Mendes. Mas é na análise de questões teóricas e críticas que se colocam ao teatro em geral e, particularmente, ao teatro em Portugal que neste número vale a pena sublinhar o que aqui se escreve sobre livros: os de Jean-Pierre Sarrazac, mas, sobretudo, os 


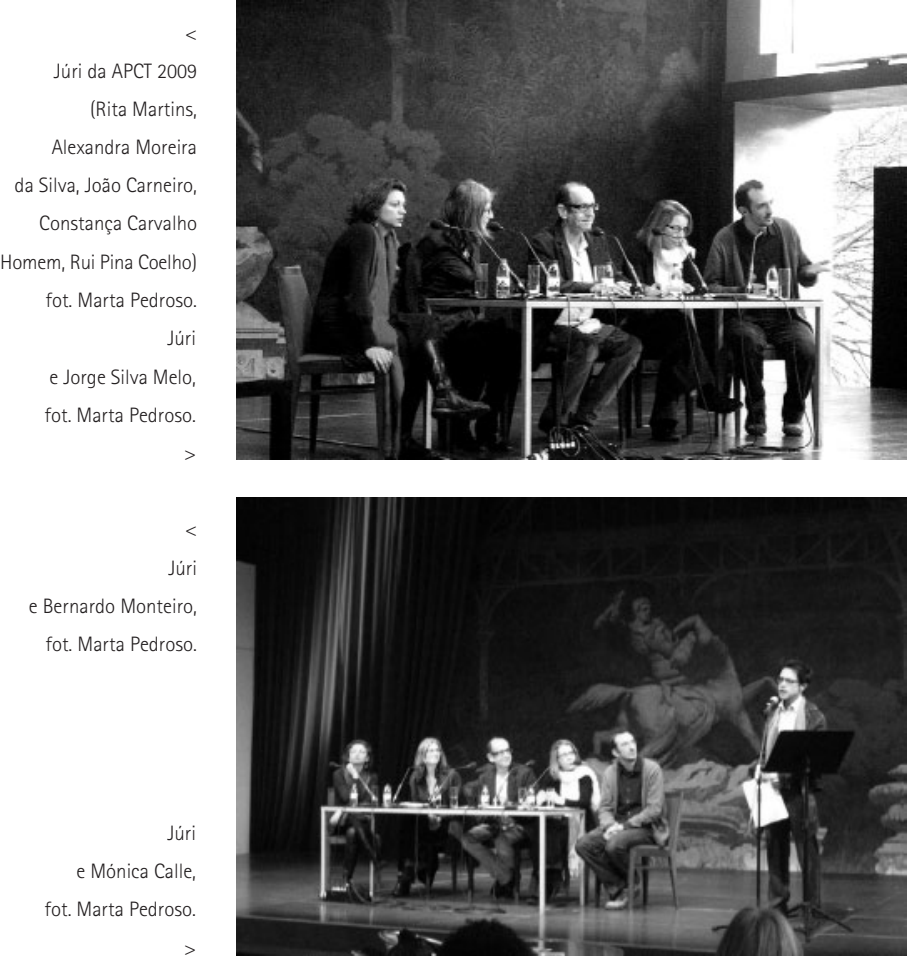

recentes estudos e reflexões dados à estampa por José Oliveira Barata, Fernando Mora Ramos, José Luís Ferreira Américo Rodrigues, Manuel Portela, Paulo Eduardo Carvalho e Rui Pina Coelho. Nesta atenção ao que entre nós se publica - e cumprindo rigorosamente o que os números de Junho da Sinais de cena vêm praticando o destaque vai ainda para a lista de publicações que Sebastiana Fadda com infinita paciência e competência vai anualmente coligindo. Mas outra importante travessia (agora interartes) habita ainda este número da revista: a atenção ao "filme" de Tiago Guedes sobre 0 mercador de Veneza, encenado por Ricardo Pais no Teatro Nacional São João, e um artigo sobre as coreografias de Joana Providência.

Todas estas formas de cruzar territórios, que a revista integra e proclama, radicam em múltiplas formas de convergência e enlace, sem as quais a publicação não seria possivel. Daí que não será por demais agradecer aos
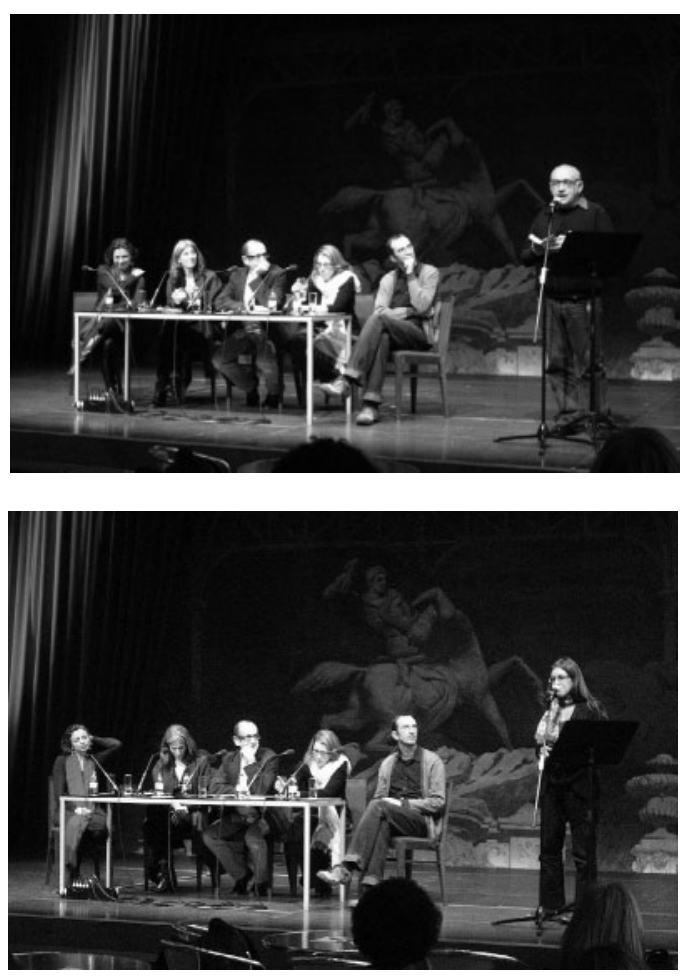

que, de forma cúmplice e generosa, escrevem, traduzem, editam e revêem as provas, e que, nesse exercicio, se encontram com os que, nas companhias de teatro, no precioso Museu Nacional do Teatro, nas suas próprias formas de fotografar, prodigamente nos oferecem a sua documentação, as suas explicações, o seu valioso contributo. Duas instituições nacionais merecem o nosso agradecimento muito especial pelo apoio que nos oferecem: o Instituto Camões e o Teatro Nacional D. Maria II. E de gratidão falamos ainda mencionando Jorge Salavisa que tantas vezes nos acolheu no seu belíssimo Jardim de Inverno (do São Luiz Teatro Municipal), como mais uma vez ocorreu para celebrar o Prémio da Crítica no passado dia 15 de Março. Travessias de lugares - artísticos, teóricos, críticos e institucionais -, mas também encontro de afinidades e afectos. Afinal, navegar é preciso, e viver também - sobretudo nestes enlaces e nestas travessias. 